\title{
Arachidonic acid inhibits the production of angiotensin-converting enzyme in human primary adipocytes via a NF-kB-dependent pathway
}

\author{
Li Xu ${ }^{1,2}$, Rita Schüler ${ }^{2}$, Chenchen $\mathrm{Xu}^{1,2}$, Nicole Seebeck ${ }^{2}$, Mariya Markova ${ }^{2}$, Veronica Murahovschi ${ }^{2}$, \\ Andreas F. H. Pfeiffer ${ }^{1,2,3}$ \\ ${ }^{1}$ Department of Endocrinology, Diabetes and Nutrition, Charité University Medicine Berlin, Campus Benjamin Franklin, Berlin, Germany; \\ ${ }^{2}$ Department of Clinical Nutrition, German Institute of Human Nutrition Potsdam-Rehbrücke (DIfE), Nuthetal, Germany; ${ }^{3}$ German Center for \\ Diabetes Research (DZD), München-Neuherberg, Germany \\ Contributions: (I) Conception and design: AFH Pfeiffer, L Xu; (II) Administrative support: AFH Pfeiffer; (III) Provision of study materials or patients: \\ L Xu, R Schüler, C Xu, N Seebeck, M Markova, V Murahovschi; (IV) Collection and assembly of data: L Xu, R Schüler, C Xu; (V) Data analysis and \\ interpretation: AFH Pfeiffer, L Xu; (VI) Manuscript writing: All authors; (VII) Final approval of manuscript: All authors. \\ Correspondence to: Prof. Andreas F. H. Pfeiffer. Department of Endocrinology, Diabetes and Nutrition, Charité University Medicine Berlin, Campus \\ Benjamin Franklin, Berlin 12200, Germany. Email: afhp@charite.de.
}

Background: The modulating mechanism of fatty acids on angiotensin-converting enzyme production (ACE) in human adipocytes is still elusive. Diet-induced regulation of the renin angiotensin system is thought to be involved in obesity and hypertension, and several previous studies have used mouse cell lines such as 3T3-L1 to investigate this. This study was carried out in human subcutaneous adipocytes for better understanding of the mechanism.

Methods: Human adipose stem cells were isolated from subcutaneous adipose tissue biopsies collected from four patients during bariatric surgery and differentiated into mature adipocytes. The mRNA expression and the activity of ACE were measured under different stimuli in cell cultures.

Results: Arachidonic acid (AA) decreased ACE mRNA expression and ACE activity in a dosedependent manner while palmitic acid had no effect. The decrease of ACE by $100 \mu \mathrm{M}$ AA was reversed by the addition of $5 \mu \mathrm{M}$ nuclear factor $-\kappa \mathrm{B}(\mathrm{NF}-\kappa \mathrm{B})$ inhibitor. Furthermore, when the production of 20-hydroxyeicosatetraenoic acid, a metabolite of AA, was stopped by the specific inhibitor HET0016 $(10 \mu \mathrm{M})$ in the culture media, the effect of AA was blocked.

Conclusions: This study indicated that AA can decrease the expression and activity of ACE in cultured human adipocytes, via an inflammatory NF- $\mathrm{BB}$-dependent pathway. Blocking 20-hydroxyeicosatetraenoic acid attenuated the ACE-decreasing effects of AA.

Keywords: Fatty acids; human adipose stem cells; 20-hydroxyeicosatetraenoic acid

Submitted Oct 16, 2020. Accepted for publication Dec 04, 2020.

doi: $10.21037 /$ atm-20-7514

View this article at: http://dx.doi.org/10.21037/atm-20-7514

\section{Introduction}

The World Health Organization defines hypertension as a pathological status in which "the blood vessels have persistently raised pressure". The deleterious consequence of hypertension is the damage it causes to affected organs, leading to an increased risk of nephropathy, vasculopathy, cardiovascular, or cerebrovascular events (1). Pathophysiologically, risk factors for hypertension include obesity, smoking, family history, high salt food intake and an overall unhealthy lifestyle and diet. Among the currently available medications for treating hypertension, angiotensin-converting enzyme (ACE) inhibitors and 
angiotensin receptor blockers are recommended as first choices (2).

ACE is a membrane-bound protein that indirectly increases blood pressure by converting angiotensin I to the active angiotensin II, a vasoconstrictor. ACE is most commonly found in endothelial and epithelial cells. ACE, in association with the other renin angiotensin system (RAS) components, was reported to be expressed in adipose tissue and cultured adipocytes (3). It is estimated that nearly $30 \%$ of the circulating angiotensin is produced by adipose tissue $(4,5)$.

Obesity is a well-known risk factor for hypertension, and obesity-related hypertension has been ascribed to an overactivated RAS (6). The activity of the adipose tissue RAS contributes to systemic high blood pressure and chronic inflammation in adipose tissue $(7,8)$. We recently reported that a high fat diet induced an increase in ACE expression in individuals with a genetic susceptibility and was associated with increased blood pressure and elevated blood glucose in a clinical human study $(9,10)$.

Arachidonic acid (AA) is a long-chain omega-6 (n-6) polyunsaturated fatty acid (PUFA) which is obtained from food or by stepwise desaturation and chain elongation of linoleic acid (LA), an essential fatty acid (EFA) (11). Marine fish, animal tissues and eggs are the major supply of AA, algae and some plants were also reported as potential sources of AA (12-14). Because of the lack of biosynthesis enzymes, humans and other mammals cannot directly synthesize AA. Therefore, they have to obtain enough AA via food or dietary intake of its precursors (15). AA is the main component of membrane lipids, and mainly metabolized by cyclooxygenase (COX), lipoxygenase (LOX), and cytochrome P450 (CYP450). AA could be converted into various metabolites such as inflammatory lipids or eicosanoids (16). AA can be converted into prostaglandins (PGs) and thromboxanes (TXs) by the cyclooxygenase (COX) pathway, the metabolites of this pathway play an important role in vessel tone regulation, mediating platelet aggregation and immune response (17-19). Through the lipoxygenase (LOX) pathway, AA can be metabolized into leukotrienes (LTs) and lipoxins (LXs). Lipoxins mainly exhibit anti-inflammatory properties (20). Besides, epoxyeicosatrienoic acids (EETs) and hydroxyeicosatetraenoic acids (HETEs) are generated through the cytochrome P450 (CYP450) pathway. And these compounds play a main part in the modulating of kidney, lung, and cardiovascular function (21). 20-HETE is considered a potent vasoconstrictor by various means.
However, it shows a potential conflicting role in regulating renal hypertension (22).

In human endothelial cells, angiotensin-converting enzyme (ACE) mRNA expression and ACE activity are increased via nuclear factor- $\kappa \mathrm{B}(\mathrm{NF}-\kappa \mathrm{B})$ pathway (23), many genes involved in vascular physiopathology are regulated by $\mathrm{NF}-\kappa \mathrm{B}$. NF- $\kappa \mathrm{B}$ activation was diminished in vivo in injured vessels by angiotensin-converting enzyme inhibitors (24). However, the mechanism involved in modulating ACE expression in adipose tissue remains elusive, and this study therefore aimed to investigate the effects of fatty acids on ACE expression and activity in human adipocytes.

In this study, primary human adipocytes were differentiated and cultured in the presence of unsaturated and saturated fatty acids. The ACE expression in the cells and ACE activity in the culture media were measured. The potential relationship between ACE and fatty acids was assessed via artificial perturbation of the $N F-\kappa B$ inflammatory pathway.

We present the following article in accordance with the MDAR reporting checklist (available at http://dx.doi. org/10.21037/atm-20-7514).

\section{Methods}

\section{Cell isolation and culture}

Human adipose stem cells (ASCs) were isolated from four patients who were participants in the LEMBAS study (dietinduced changes in Liver fat and Energy Metabolism prior to Bariatric Surgery) (25). This clinical intervention study was approved by the Ethics Committee of the Charité University Medicine in Berlin (Application no.EA4/006/15) in accordance with the Declaration of Helsinki and registered at www.drks.de (DRKS00009509). All four study participants were morbidly obese with a body mass index (BMI) above $40 \mathrm{~kg} / \mathrm{m}^{2}$. Their subcutaneous adipose tissue biopsies were collected during the Roux-en-Y gastric bypass operation. Informed consent was acquired from each individual prior to surgery.

ASCs were isolated following the method modified from Lee et al. (26). Briefly, $5 \mathrm{mg}\left(2-3 \mathrm{~mm}^{3}\right)$ of adipose tissue (AT) was minced into small pieces. The minced tissue was rinsed by phosphate buffer saline (PBS), passed through a $250 \mu \mathrm{m}$ funnel-shaped mesh and then digested in Dulbecco's Modified Eagle Medium (DMEM)/ F12 (Thermo Fisher Scientific, Waltham, MA, USA) containing collagenase I $(1 \mathrm{mg} / \mathrm{mL})$ (Sigma Aldrich 
Chemie, Steinheim, Germany) at $37^{\circ} \mathrm{C}$ for 2 hours with constant shaking (100 rpm). Subsequently, the digested AT was filtered through a $250 \mu \mathrm{m}$ mesh and the filtrate, which contains the ASCs, was collected and centrifuged at $500 \times \mathrm{g}$ for 10 minutes. Afterwards, the upper fat layer and the middle medium layer above the cell pellet in the tube were removed. The cells were resuspended after adding red blood cell (RBC) lysis buffer (Thermo Fisher Scientific, Waltham, MA, USA) to diminish the $\mathrm{RBC}$ cells for better attachment. After centrifugation at $500 \times \mathrm{g}$ for 5 minutes, the cells were resuspended again with Preadipocyte Growth Medium containing Preadipocyte Growth Medium SupplementMix (Promo Cell, Heidelberg, Germany) and 1\% penicillin/streptomycin (Sigma Aldrich Chemie, Steinheim, Germany) and cultured in a $15 \mathrm{~mL}$ flask. Cells were maintained in a $37^{\circ} \mathrm{C}$ incubator with $5 \% \mathrm{CO}_{2}$ and refed every $2-3$ days until $80-90 \%$ confluence, and then cultured for 14 days in 12 -well plates in differentiation medium which contained DMEM/F12, 1\% penicillin/streptomycin, $500 \mu \mathrm{M}$ IBMX, $25 \mathrm{nM}$ dexamethasone, $0.2 \mathrm{nM}$ triiodothyronine (T3), $33 \mu \mathrm{M}$ D-biotin, $15 \mathrm{mM}$ pantothenate, $20 \mathrm{nM}$ human insulin, $0.01 \mathrm{mg} / \mathrm{mL}$ transferrin, and $2 \mu \mathrm{M}$ rosiglitazone (all chemicals were purchased from Sigma Aldrich Chemie, Steinheim, Germany). Differentiation of the mature adipocytes was confirmed by oil red $\mathrm{O}$ stain. NF$\kappa \mathrm{B}$ inhibitor BAY117082 and 20-hydroxyeicosatetraenoic acid (20-HETE) production inhibitor HET0016 (27) were purchased from Cayman Chemical (Ann Arbor, MI, USA).

\section{Oil red $O$ staining}

After 14 days of adipogenesis, differentiated adipocytes were washed with sterile PBS and fixed in 10\% formaldehyde (Sigma Aldrich Chemie, Steinheim, Germany) for 1 hour of incubation at room temperature. Oil red $\mathrm{O}$ was prepared by mixing oil red $\mathrm{O}$ stock solution with deionized water in the ratio of 3:2. Thereafter, adipocytes were gently rinsed with water, and $60 \%$ isopropanol (Sigma Aldrich Chemie, Steinheim, Germany) was added for 5 minutes. Finally, the adipogenic cultures were incubated in oil red $\mathrm{O}$ for 10 minutes, rinsed with tap water until the water ran clear, and analyzed under the microscope.

\section{Free fatty acids preparation and treatment}

Palmitate (Sigma Aldrich Chemie, Steinheim, Germany) was dissolved completely in ethanol at $70{ }^{\circ} \mathrm{C}$ and then complexed with fatty acid-free bovine serum albumin (BSA) (Sigma Aldrich Chemie, Steinheim, Germany) at $55^{\circ} \mathrm{C}$ for 10 minutes yielding the final palmitic acid (PA) stock solution of $5 \mathrm{mM}$. The working solution of $500 \mu \mathrm{M}$ (28-30) was prepared with DMEM before experiments.

Arachidonic acid (AA) (Cayman Chemical, Ann Arbor, Mi, USA) was complexed with fatty acid-free BSA. The working solutions of 50,100 , or $200 \mu \mathrm{M}$ were prepared with DMEM before the experiments.

After differentiation for 7 days (approximately 80\% differentiation as estimated by lipid droplets), the cell culture medium was changed to DMEM with $1 \% \mathrm{BSA}$ and without fatty acids, or with PA 500, AA 50, 100, or $200 \mu \mathrm{M}$, for the purpose of determining the effects of saturated and unsaturated fatty acids. Subsequently, AA $100 \mu \mathrm{M}$ was used in further experiments (see results section) and other research reports (31-33). To explore the effects of NF- $\kappa B$ pathway inhibition, adipocytes were pretreated with $5 \mu \mathrm{M}$ BAY117082 for 1 hour and then treated with either DMEM + 0.1\% BSA or DMEM + 0.1\% BSA + $100 \mu \mathrm{M}$ AA for 24 hours. In order to ascertain the effects of 20 HETE, adipocytes were pretreated with $10 \mu \mathrm{M}$ HET0016, the specific inhibitor of 20-HETE (27), for 1 hour and then treated with either DMEM + 0.1\% BSA or DMEM + $0.1 \%$ $\mathrm{BSA}+100 \mu \mathrm{M}$ AA for 24 hours.

\section{Quantitative real-time polymerase chain reaction ( $q R T$ - PCR)}

Total RNA was extracted by using the Nucleospin ${ }^{\circledR}$ RNA II Kit (Macherey-Nagel, Düren, Germany), according to the manufacturer's protocol. cDNA was synthesized from $1 \mu \mathrm{g}$ of RNA of each sample by using the high capacity cDNA reverse transcription kit (Applied Biosystems by Life Technologies, Carlsbad, CA, USA). QRT-PCR was performed using the power SYBR Green PCR master mix (Applied Biosystems by Life Technologies, Carlsbad, CA, USA) and detected in triplicates with the ABI $\mathrm{ViiA}^{\mathrm{TM}} 7$ Real time PCR system (Applied Biosystems by Life Technologies, Carlsbad, CA, USA). The samples were normalized to a ribosomal protein large P0 (RPLP0). The primers synthesized by Thermo Fisher Scientific (Waltham, MA, USA) are shown in Table 1.

\section{Assessment of ACE activity}

ACE activity was determined in triplicate by measuring the fluorescence of the product generated by the specific 
Table 1 Primers used in the study

\begin{tabular}{lll}
\hline Gene & Forward & Reverse \\
\hline RPLPO & 5'-GCTTCCTGGAGGGTGTCC-3' & 5'-GGACTCGTTTGTACCCGTTG-3' \\
ACE & 5'-CAGAACACCACTATCAAGCGGA-3' & 5'-CACGCTGTAGGTGGTTTCCAT-3' \\
\hline
\end{tabular}

ACE, angiotensin-converting enzyme.

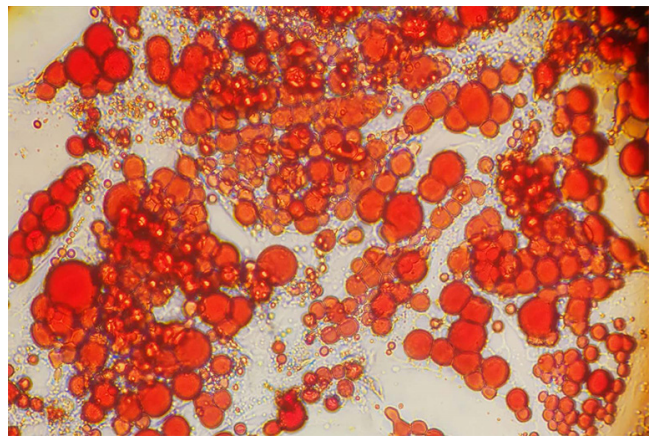

Figure 1 The oil red $\mathrm{O}$ staining of differentiated cells photographed using a microscope $(\times 100)$. Lipid droplets are stained in red.

substrate Abz-Gly-Phe ( $\mathrm{NO}_{2}$ )-Pro (Bachem, Bubendorf, Switzerland, cat. no. M-1100). The protocol designed by Sentandreu et al. was followed (34). Briefly, $50 \mu \mathrm{L}$ testing samples and standard solutions of eight different concentrations were added into a 96-well microplate. Captopril-inhibition and blank-contrast wells were also included. A $200 \mu \mathrm{L}$ substrate working solution, which was mixed by diluting M1100 in $150 \mathrm{mM}$ Tris-base buffer ( $\mathrm{pH}$ 8.3) with $1.125 \mathrm{M} \mathrm{NaCl}$, was added into each well to initiate the enzyme reaction. Fifty $\mu \mathrm{L}$ of samples were incubated in a final volume of $300 \mu \mathrm{L}$ with $0.45 \mathrm{mM}$ of specific substrate. The plate was read two times with a Tecan infinite M200 microplate reader at an excitation wavelength of $365 \mathrm{~nm}$, and an emission wavelength of $425 \mathrm{~nm}$. The first measurement was performed at room temperature when the reaction was initiated, and the second after incubating the solution at $37^{\circ} \mathrm{C}$ for 30 minutes. ACE activity was determined by the fluorescence emission differences between the incubation periods.

\section{Statistical analysis}

Statistical data were processed using SPSS 20.0 (IBM SPSS, Chicago, IL, USA). Results are expressed as the mean \pm SD and data were analyzed using student's $t$-test for unpaired samples or the one-way ANOVA for multiple comparisons among groups.

\section{Results}

\section{Evaluation of the cultured cells}

In order to ascertain the success of the adipocyte differentiation, oil red $\mathrm{O}$ staining was performed. The cultured cells were characterized with typical red oil-stained lipid drops distributed in the cytosol (Figure 1). At least $80 \%$ of the cells were fat cells according to the staining. Combined with some morphological features, the cultured cells qualified for the current study according to the optimal protocol (26).

\section{ACE expression in the presence of different fatty acids}

Two kinds of fatty acids were selected to stimulate the adipocytes. For the saturated fatty acids, PA was selected as the example. Neither the mRNA expression of ACE nor the ACE activity in the culture media were affected by the addition of PA (Figure 2A,B). On the contrary, in the presence of $\mathrm{AA}$, an inflammation-related unsaturated fatty acid, both the mRNA expression of ACE and the ACE activity in the culture media decreased dose-dependently (Figure 2C,D). At the dose of $100 \mu \mathrm{M}$, AA inhibited the expression of ACE in adipocytes, which in turn resulted in lowered ACE activity in the media (Figure 2E,F). The concentration of $100 \mu \mathrm{M}$ was chosen for the subsequent reversal experiments of AA effects.

\section{Involvement of the NF- $\kappa B$ patbway in the suppression of ACE}

In adipose tissue, free fatty acids have been found to activate the RAS through the NF- $\mathrm{KB}$ pathway (35). In light of this, we investigated whether inhibiting the NF- $\kappa \mathrm{B}$ pathway could rescue the expression of ACE. Compared to control cells, culture of the adipocytes in the presence of the NF- $\kappa \mathrm{B}$ 

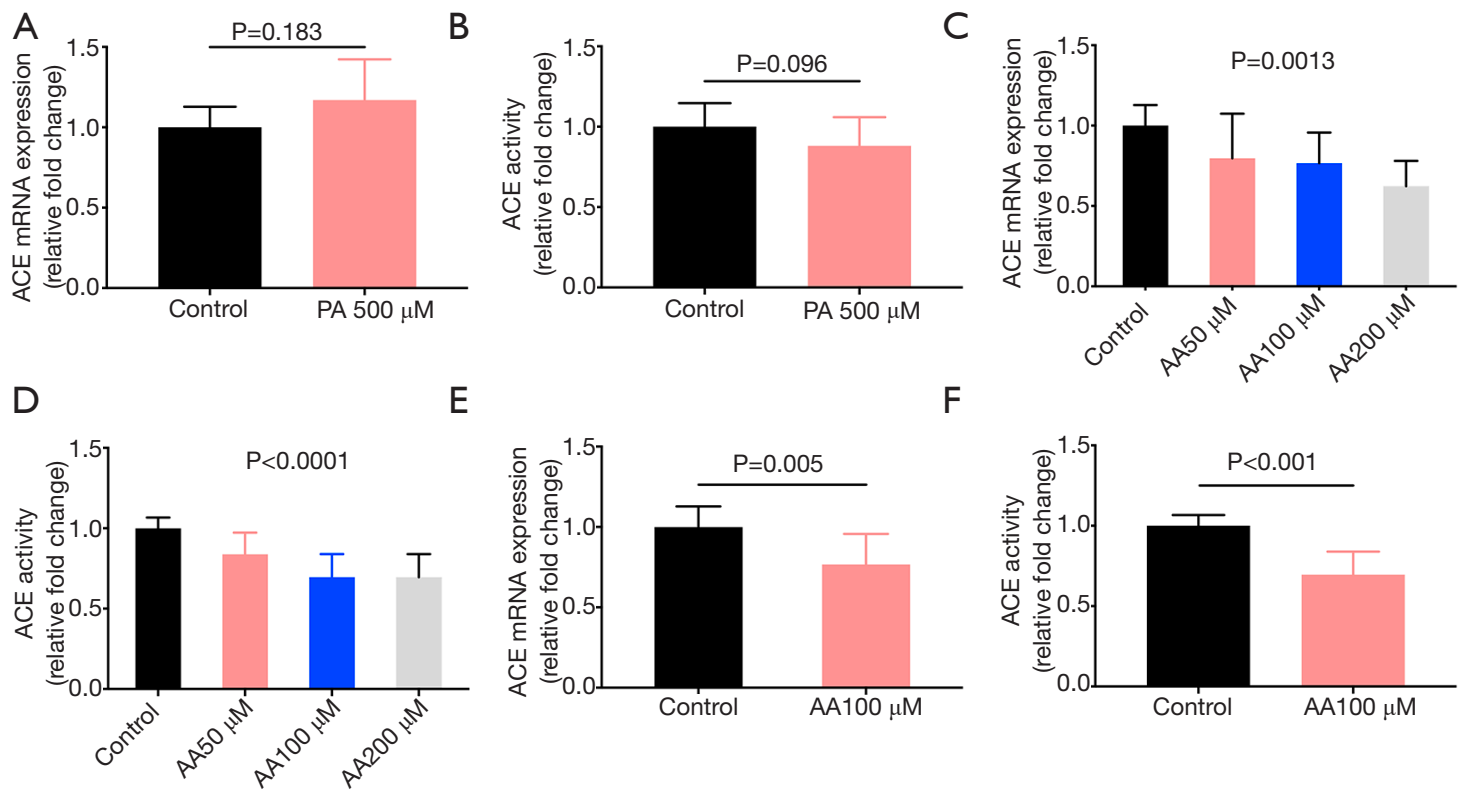

Figure 2 The angiotensin-converting enzyme (ACE) mRNA level in the cell extract and ACE activity in the culture media are measured under the stimuli of palmic acid (PA, $500 \mu \mathrm{M}$ ) or arachidonic acid (AA, 50, 100, $200 \mu \mathrm{M}$ ), respectively. (A) In the presence of $500 \mu \mathrm{M}$ PA, the mRNA expression of ACE in the fat cell extract is not affected compared with controls $(\mathrm{P}=0.183)$. (B) Similar results are obtained for ACE activity in the culture media treated with the same PA concentration $(\mathrm{P}=0.096)$. (C) In the presence of AA at different concentrations, the expression of ACE mRNA in the culture media shows a statistical difference $(\mathrm{P}=0.0013)$. (D) ACE activity shows a similar response under the same condition $(\mathrm{P}<0.0001)$. As the dosage of AA is increased, the ACE expression and activity show trends of decline ( $\mathrm{n}=3$ ). The effect of $100 \mu \mathrm{M}$ AA on ACE expression and ACE activity are displayed in part $(\mathrm{E})$ and $(\mathrm{F})$, respectively $(\mathrm{P}=0.005, \mathrm{P}<0.001)$. All values are expressed as mean \pm SD of 3 experiments, and each experiment is conducted in triplicate.

pathway inhibitor (BAY117082) increased ACE expression in the presence of AA (Figure $3 A$ ). In other words, the introduction of the NF- $\mathrm{\kappa B}$ inhibitor completely blocked the effects of AA on ACE expression.

20-Hydroxy-5, 8, 11, 14-eicosatetraenoic acid (20-HETE) is a cytochrome P450 (CYP)-derived metabolite of AA which was shown to play a complex role in blood pressure and also blood sugar regulation (36,37). Activation of RAS was reported to be 20-HETE dependent $(38,39)$. The effects from BAY117082 led us to postulate that the response to the NF- $\kappa \mathrm{B}$ pathway inhibition might be related to 20-HETE metabolism of AA. We found that the inclusion of 20-HETE inhibitor HET0016 could compromise the effects of AA (Figure 3B). Activity of ACE in the media was also elevated compared to that of the AAtreated group (Figure 3C). When a mere $10 \mathrm{nM}$ 20-HETE was added in the culture media of adipocytes, ACE activity was suppressed (Figure 3D).

\section{Discussion}

Dietary fat, in the form of fatty acids, has been found to exert different effects on preadipocyte differentiation and proliferation (40). Excessive saturated fatty acid intake and accumulation have been found to have detrimental effects on metabolism, resulting in insulin resistance, obesity, vascular disease, and hypertension. Obesity is known to activate the RAS pathway (41), and we previously reported that the introduction of a diet high in saturated fat elevates ACE even in normal weight healthy young study participants and leads to increases in blood pressure and blood glucose levels $(9,10)$. The adipose tissue ACE gene expression was increased significantly in response to 6 weeks of a high fat diet, and energy consumption from total fat and saturated fat was $45 \%$ and $18 \%$, respectively. We assumed that the high fat diet activated the reninangiotensin system with increased ACE expression in human adipose tissue. In this study, PA stimulation seemed 

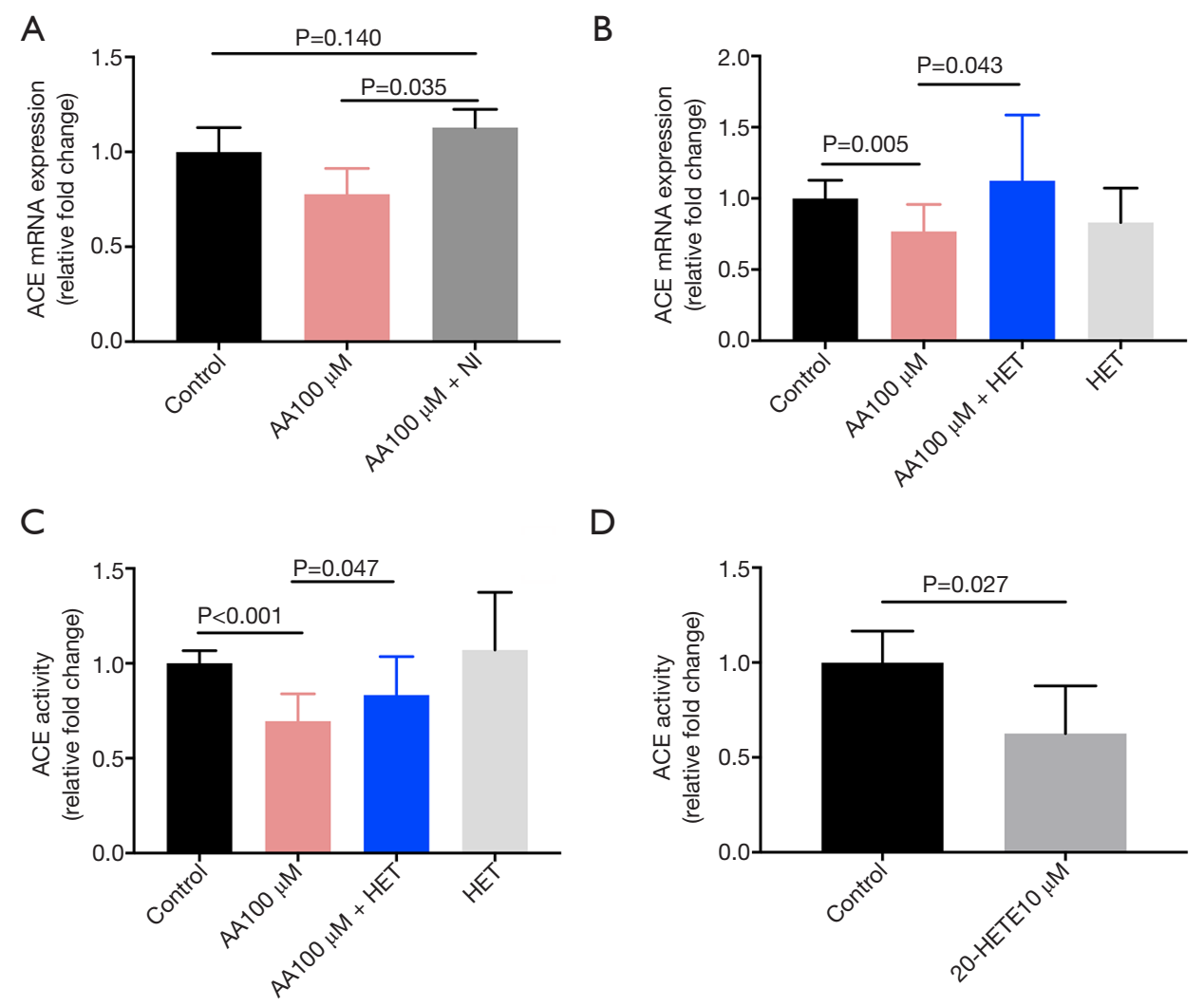

Figure 3 The inhibitory effect of arachidonic acid on ACE production in human subcutaneous adipocytes was reversed by NF-kB inhibitor (NI) and 20-HETE inhibitor HET0016 (HET). (A) The reversal of the inhibition of angiotensin-converting enzyme (ACE) mRNA expression in the presence of $100 \mu \mathrm{M}$ arachidonic acid (AA100) by the $5 \mu \mathrm{M}$ NF-kB inhibitor BAY117082 (NI) in cultured adipocytes (n=3). (B) $10 \mu \mathrm{M}$ 20-HETE inhibitor HET0016 (HET) competes off the inhibition of ACE mRNA expression by $100 \mu M$ AA (AA100) ( $\mathrm{n}=3$ ). (C) Reversal of the AA-induced (100 $\mu \mathrm{M}$, AA100) inhibition of ACE activity by $10 \mu M$ HET0016 (HET) (n=3). (D) ACE activity is down-regulated when a mere $10 \mathrm{nM} 20$-HETE is added in the culture media of adipocytes. All values are expressed as mean \pm SD of 3 experiments, and each experiment is conducted in triplicate.

to have no effect on the cultured adipocytes (Figure 2). This finding might be ascribed to the fact that saturated fatty acids need to be deposited in adipocytes in an esterified form. The data suggests that the increase in ACE seen in the presence of a high fat diet is not a direct consequence of the interaction of PA with fat cells.

AA is a typical n-6 polyunsaturated fatty acid found in daily food which can be generated by elongation and desaturation from linoleic acid, a predominant $n-6$ fatty acid in some plant oils, although increased intake may not necessarily result in increased levels of AA in humans (42). It was reported to stimulate preadipocyte differentiation in a cyclooxygenase-dependent manner (43). In this assay, AA was selected as the example of an unsaturated fatty acid to stimulate adipocytes. We found that in the presence of AA, cultured adipocytes exhibited lowered expression of ACE (Figure 2E) which, in turn, resulted in the lowered ACE activity in the media and might be considered a protective effect (Figure 2F).

Free AA can be metabolized through four enzymatic and one non-enzymatic pathway. The enzymatic pathways include cyclooxygenase (COX), lipoxygenase (LOX), and cytochrome p450 (CYP 450). The CYP 450 pathway involves two enzymes: CYP450 epoxygenase, and CYP450 $\omega$-hydroxylase, giving rise to EETs and 20HETE, respectively $(31,44)$. Other metabolites include prostaglandins (PGs), prostacyclin, thromboxane (Tx), hydroperoxyeicosatetraenoic acid (HPETE), leukotrienes (LTs), lipoxins, hypoxins, and anandamide. The nonenzymatic pathway is important for the production of 
isoprostanes and nitroeicosatetraenoic acid. Most of the AA metabolites are highly bioactive and involved in various crucial vital processes.

20-HETE induces oxidative stress, increases BMI, and is related to metabolic syndrome. In human mesenchymal stem cell-derived adipocytes, the expression levels of major 20-HETE synthases, CYP4F2, decreased during adipocyte differentiation which means lower levels of endogenous 20-HETE exist; however, exogenous administration of 20-HETE $(0.1-1 \mu \mathrm{M})$ increased adipogenesis in a dosedependent manner (45). 20-HETE has been proven to be one of the activators of NF- $\mathrm{KB}$ (46). In this study, we found that blocking the 20-HETE synthesis using HET0016 reversed the AA-suppressed ACE expression and ACE activity (Figure $3 A, B, C$ ), and subsequently, we found that adding a mere $10 \mathrm{nM}$ 20-HETE into the culture media down-regulated the ACE activity of unpretreated adipocytes (Figure 3D). Thus, we postulate that AA exerts at least part of its ACE-suppressing effect through its metabolite 20HETE, and inhibiting 20-HETE synthesis can reverse the ACE-suppressing effect. This is not in accordance with a previous report which reported that 20-HETE activates ACE expression through the NF-kB pathway (39). Thus, in this study, a NF- $\kappa \mathrm{B}$ inhibitor was also employed to block the activation of this pathway. Clearly, the decreased expression of ACE was also reversed by this perturbation (Figure 3).

Notably, our findings have been obtained in cultured human primary adipocytes, therefore differences might be due to tissue and cell type specificities. Human preadipocytes have been shown no differences between DM and non-diabetes mellitus (NDM) patients in accumulating cytoplasmic lipid and upregulating expression of adipogenic genes (47). We can not exclude that the morbid patients undergo epigenetic changes due to metabolic conditions. On the other hand, we suppose that the effects of fatty acids on ACE would be more expressed in adipocytes from obese patients and patients with T2D. Due to the high costs and complexity of this kind of cell culture, ASCs of 3-4 patients are usually used to investigate the pathophysiological mechanisms (48).

Previous reports utilized endothelial cells or adipocytes from other tissues. To our knowledge, this is the first use of adipocytes originating from human subcutaneous stem cells to evaluate the effects of AA relevant to the RAS. In addition, the ASCs were isolated by biopsies from four morbidly obese patients who each had a BMI above $40 \mathrm{~kg} / \mathrm{m}^{2}$, potentially resulting in an abnormal cell state.
These ASCs may also be influenced by obesity-related sources in terms of differentiation and physiological function.

Even for adipocytes, the regulation of RAS was reported to be depot specific. For example, according to some reports, angiotensin can only increase fat mass, fat cell sizes, adipose and systemic inflammation in visceral adipose depots but not in subcutaneous depots (6). Thus, the findings described in this study might imply that cell type selection is crucial to data interpretation in the study of RAS functions. However, the current findings may be limited by the cell culture study, and more animal or human studies are needed for confirmation.

The result suggests that the inflammatory NF$\kappa \mathrm{B}$ pathway exerts beneficial effects by lowering ACE expression. Indeed, postprandial inflammation is a common phenomenon and may exert beneficial regulatory effects in adipose tissue as suggested by previous studies (49). Indeed, we observed long-term metabolic improvements upon increasing dietary intake of n-6 fatty acids despite acute increases in adipose inflammatory responses (50). Moreover, elevated levels of AA are not linked to increased risks of cardiovascular disease in large epidemiological metaanalyses (51). Our data, therefore, may help to explain the long-term beneficial effects of increased intake of $n-6$ fatty acids (52).

The limitations of this study relate to the in vitro nature of the investigation which differs from an in vivo situation. Moreover, the primary adipocytes were obtained from four morbidly obese individuals and may have undergone epigenetic changes due to the metabolic condition of the patients. Also, larger sample size trails will bring more evidence.

\section{Conclusions}

This study primarily demonstrated that subcutaneous adipocytes responded differentially to saturated and unsaturated fatty acids in ACE production. We have provided initial evidence that interfering with adipocyte metabolism might be a potential method to modulate the RAS and its subsequent pathological and physiological events.

\section{Acknowledgments}

We would like to thank all of the study participants for their cooperation and valuable help. We also wish to acknowledge 
Katrin Sprengel and Andrea Borchert for their excellent technical assistance.

Funding: None.

\section{Footnote}

Reporting Checklist: The authors have completed the MDAR reporting checklist. Available at http://dx.doi.org/10.21037/ atm-20-7514

Data Sharing Statement: Available at http://dx.doi. org/10.21037/atm-20-7514

Conflicts of Interest: All authors have completed the ICMJE uniform disclosure form (available at http://dx.doi. org/10.21037/atm-20-7514). The authors have no conflicts of interest to declare.

Ethical Statement: The authors are accountable for all aspects of the work in ensuring that questions related to the accuracy or integrity of any part of the work are appropriately investigated and resolved. This clinical intervention study was approved by the Ethics Committee of the Charite University Medicine in Berlin (Application no. EA4/006/15) in accordance with the Declaration of Helsinki and registered at www.drks.de (DRKS00009509). Informed consent was acquired from each individual prior to surgery.

Open Access Statement: This is an Open Access article distributed in accordance with the Creative Commons Attribution-NonCommercial-NoDerivs 4.0 International License (CC BY-NC-ND 4.0), which permits the noncommercial replication and distribution of the article with the strict proviso that no changes or edits are made and the original work is properly cited (including links to both the formal publication through the relevant DOI and the license). See: https://creativecommons.org/licenses/by-nc-nd/4.0/.

\section{References}

1. Eirin A, Lerman A, Lerman LO. Enhancing Mitochondrial Health to Treat Hypertension. Curr Hypertens Rep 2018;20:89.

2. Wright JM, Musini VM, Gill R. First-line drugs for hypertension. Cochrane Database Syst Rev 2018;4:CD001841.

3. Pahlavani M, Kalupahana NS, Ramalingam L, et al.
Regulation and Functions of the Renin-Angiotensin System in White and Brown Adipose Tissue. Compr Physiol 2017;7:1137-50.

4. Massiera F, Bloch-Faure M, Ceiler D, et al. Adipose angiotensinogen is involved in adipose tissue growth and blood pressure regulation. FASEB J 2001;15:2727-9.

5. Faloia E, Gatti C, Camilloni MA, et al. Comparison of circulating and local adipose tissue renin-angiotensin system in normotensive and hypertensive obese subjects. J Endocrinol Invest 2002;25:309-14.

6. Chelo D, Mah EM, Chiabi EN, et al. Prevalence and factors associated with hypertension in primary school children, in the centre region of Cameroon. Transl Pediatr 2019;8:391-7.

7. Ranjbar R, Shafiee M, Hesari A, et al. The potential therapeutic use of renin-angiotensin system inhibitors in the treatment of inflammatory diseases. Journal of cellular physiology 2019;234:2277-95.

8. Iwai M, Kanno H, Tomono Y, et al. Direct renin inhibition improved insulin resistance and adipose tissue dysfunction in type 2 diabetic KK-A(y) mice. J Hypertens 2010;28:1471-81.

9. Schüler R, Osterhoff MA, Frahnow T, et al. HighSaturated-Fat Diet Increases Circulating AngiotensinConverting Enzyme, Which Is Enhanced by the rs4343 Polymorphism Defining Persons at Risk of NutrientDependent Increases of Blood Pressure. J Am Heart Assoc 2017;6:e004465.

10. Schüler R, Osterhoff MA, Frahnow T, et al. Dietary Fat Intake Modulates Effects of a Frequent ACE Gene Variant on Glucose Tolerance with association to Type 2 Diabetes. Sci Rep 2017;7:9234.

11. Tallima H, El Ridi R. Arachidonic acid: Physiological roles and potential health benefits - A review. J Adv Res 2018;11:33-41.

12. Bigogno C, Khozin-Goldberg I, Adlerstein D, et al. Biosynthesis of arachidonic acid in the oleaginous microalga Parietochloris incisa (Chlorophyceae): Radiolabeling studies. Lipids 2002;37:209-16.

13. Ouyang LL, Chen SH, Li Y, et al. Transcriptome analysis reveals unique $\mathrm{C} 4$-like photosynthesis and oil body formation in an arachidonic acid-rich microalga Myrmecia incisa Reisigl H4301. BMC Genomics 2013;14:396.

14. Beike AK, Jaeger C, Zink F, et al. High contents of very long-chain polyunsaturated fatty acids in different moss species. Plant Cell Reports 2014;33:245-54.

15. Huang Y-S, Pereira SL, Leonard AE. Enzymes for transgenic biosynthesis of long-chain polyunsaturated fatty 
acids. Biochimie 2004;86:793-8.

16. Wang T, Fu X, Chen Q, et al. Arachidonic Acid Metabolism and Kidney Inflammation. Int J Mol Sci 2019;20:3683.

17. Kabashima K, Murata T, Tanaka H, et al. Thromboxane A2 modulates interaction of dendritic cells and $\mathrm{T}$ cells and regulates acquired immunity. Nat Immunol 2003;4:694-701.

18. Cogolludo A, Moreno L, Bosca L, et al. Thromboxane A2-induced inhibition of voltage-gated $\mathrm{K}+$ channels and pulmonary vasoconstriction: role of protein kinase Czeta. Circ Res 2003;93:656-63.

19. Hartwig JH, Bokoch GM, Carpenter CL, et al. Thrombin receptor ligation and activated rac uncap actin filament barbed ends through phosphoinositide synthesis in permeabilized human platelets. Cell 1995;82:643-53.

20. Serhan CN. Lipoxins and aspirin-triggered 15-epilipoxins are the first lipid mediators of endogenous antiinflammation and resolution. Prostaglandins Leukot Essent Fatty Acids 2005;73:141-62.

21. Roman RJ. P-450 metabolites of arachidonic acid in the control of cardiovascular function. Physiol Rev 2002;82:131-85.

22. Zhang C, Booz GW, Yu Q, et al. Conflicting roles of 20HETE in hypertension and renal end organ damage. European Journal of Pharmacology 2018;833:190-200.

23. Garcia V, Shkolnik B, Milhau L, et al. 20-HETE Activates the Transcription of Angiotensin-Converting Enzyme via Nuclear Factor- $\kappa \mathrm{B}$ Translocation and Promoter Binding. J Pharmacol Exp Ther 2016;356:525-33.

24. Ruiz-Ortega M, Lorenzo O, Rupérez M, et al. Angiotensin II activates nuclear transcription factor kappaB through AT(1) and AT(2) in vascular smooth muscle cells: molecular mechanisms. Circ Res 2000;86:1266-72.

25. Xu C, Markova M, Seebeck N, et al. High-protein diet more effectively reduces hepatic fat than low-protein diet despite lower autophagy and FGF21 levels. Liver Int 2020. [Epub ahead of print]. doi: 10.1111/liv.14596.

26. Lee MJ, Fried SK. Optimal protocol for the differentiation and metabolic analysis of human adipose stromal cells. Methods Enzymol 2014;538:49-65.

27. Miyata N, Taniguchi K, Seki T, et al. HET0016, a potent and selective inhibitor of 20-HETE synthesizing enzyme. Br J Pharmacol 2001;133:325-9.

28. Reaven GM, Hollenbeck C, Jeng CY, et al. Measurement of plasma glucose, free fatty acid, lactate, and insulin for 24 $\mathrm{h}$ in patients with NIDDM. Diabetes 1988;37:1020-4.

29. Bradley RL, Fisher FFM, Maratos-Flier E. Dietary fatty acids differentially regulate production of TNF-alpha and IL-10 by murine 3T3-L1 adipocytes. Obesity (Silver Spring) 2008;16:938-44.

30. Ng YW, Say YH. Palmitic acid induces neurotoxicity and gliatoxicity in SH-SY5Y human neuroblastoma and T98G human glioblastoma cells. PeerJ 2018;6:e4696.

31. Hanna VS, Hafez EAA. Synopsis of arachidonic acid metabolism: A review. J Adv Res 2018;11:23-32.

32. Brash AR. Arachidonic acid as a bioactive molecule. J Clin Invest 2001;107:1339-45.

33. Rukoyatkina N, Shpakova V, Panteleev M, et al. Multifaceted effects of arachidonic acid and interaction with cyclic nucleotides in human platelets. Thromb Res 2018;171:22-30.

34. Sentandreu MA, Toldra F. A fluorescence-based protocol for quantifying angiotensin-converting enzyme activity. Nat Protoc 2006;1:2423-7.

35. Sun J, Luo J, Ruan Y, et al. Free Fatty Acids Activate Renin-Angiotensin System in 3T3-L1 Adipocytes through Nuclear Factor-kappa B Pathway. J Diabetes Res 2016;2016:1587594.

36. Gilani A, Pandey V, Garcia V, et al. High-fat diet-induced obesity and insulin resistance in CYP4a14(-/-) mice is mediated by 20-HETE. Am J Physiol Regul Integr Comp Physiol 2018;315:R934-44.

37. Wu CC, Gupta T, Garcia V, et al. 20-HETE and blood pressure regulation: clinical implications. Cardiol Rev 2014;22:1-12.

38. Sodhi K, Wu CC, Cheng J, et al. CYP4A2-induced hypertension is 20-hydroxyeicosatetraenoic acid- and angiotensin II-dependent. Hypertension 2010;56:871-8.

39. Garcia V, Shkolnik B, Milhau L, et al. 20-HETE Activates the Transcription of Angiotensin-Converting Enzyme via Nuclear Factor-kappaB Translocation and Promoter Binding. J Pharmacol Exp Ther 2016;356:525-33.

40. Petersen RK, Jorgensen C, Rustan AC, et al. Arachidonic acid-dependent inhibition of adipocyte differentiation requires PKA activity and is associated with sustained expression of cyclooxygenases. J Lipid Res 2003;44:2320-30.

41. Ramalingam L, Menikdiwela K, LeMieux M, et al. The renin angiotensin system, oxidative stress and mitochondrial function in obesity and insulin resistance. Biochim Biophys Acta Mol Basis Dis 2017;1863:1106-14.

42. Rett BS, Whelan J. Increasing dietary linoleic acid does not increase tissue arachidonic acid content in adults consuming Western-type diets: a systematic review. Nutr Metab (Lond) 2011;8:36. 
43. Gaillard D, Negrel R, Lagarde M, et al. Requirement and role of arachidonic acid in the differentiation of preadipose cells. Biochem J 1989;257:389-97.

44. Sonnweber T, Pizzini A, Nairz M, et al. Arachidonic Acid Metabolites in Cardiovascular and Metabolic Diseases. Int J Mol Sci 2018;19:3285.

45. Kim DH, Puri N, Sodhi K, et al. Cyclooxygenase-2 dependent metabolism of 20-HETE increases adiposity and adipocyte enlargement in mesenchymal stem cellderived adipocytes. J Lipid Res 2013;54:786-93.

46. Ishizuka T, Cheng J, Singh H, et al.

20-Hydroxyeicosatetraenoic acid stimulates nuclear factorkappaB activation and the production of inflammatory cytokines in human endothelial cells. J Pharmacol Exp Ther 2008;324:103-10.

47. Baker NA, Muir LA, Washabaugh AR, et al. DiabetesSpecific Regulation of Adipocyte Metabolism by the Adipose Tissue Extracellular Matrix. J Clin Endocrinol Metab 2017;102:1032-43.

48. Murahovschi V, Pivovarova O, Ilkavets I, et al. WISP1 is a novel adipokine linked to inflammation in obesity.

Cite this article as: $\mathrm{Xu} \mathrm{L}$, Schüler $\mathrm{R}, \mathrm{Xu} C$, Seebeck N, Markova M, Murahovschi V, Pfeiffer AFH. Arachidonic acid inhibits the production of angiotensin-converting enzyme in human primary adipocytes via a NF- $\kappa \mathrm{B}$-dependent pathway. Ann Transl Med 2020;8(24):1652. doi: 10.21037/atm-20-7514
Diabetes 2015;64:856-66.

49. Wernstedt Asterholm I, Tao C, Morley TS, et al. Adipocyte inflammation is essential for healthy adipose tissue expansion and remodeling. Cell Metab 2014;20:103-18.

50. Kruse M, von Loeffelholz C, Hoffmann D, et al. Dietary rapeseed/canola-oil supplementation reduces serum lipids and liver enzymes and alters postprandial inflammatory responses in adipose tissue compared to olive-oil supplementation in obese men. Mol Nutr Food Res 2015;59:507-19.

51. Chowdhury R, Warnakula S, Kunutsor S, et al. Association of dietary, circulating, and supplement fatty acids with coronary risk: a systematic review and meta-analysis. Ann Intern Med 2014;160:398-406.

52. Wu JH, Lemaitre RN, King IB, et al. Circulating omega-6 polyunsaturated fatty acids and total and cause-specific mortality: the Cardiovascular Health Study. Circulation 2014;130:1245-53.

(English Language Editor: D. Fitzgerald) 